Гаращенко О. В., к.т.н., Гаращенко В. І., к.т.н, доцент, Сафоник А. П., д.т.н., професор, Соляк Л. В., ст. викладач (Національний університет водного господарства та природокористування, м. Рівне)

\title{
ЕКСПЕРИМЕНТАЛЬНІ ДОСЛІДЖЕННЯ ПАРАМЕТРІВ ЕЛЕКТРОМАГНІТНИХ ФІЛЬТРІВ
}

Наведені результати досліджень з розподілу індукції магнітного поля у циліндричному корпусі, заповненому феромагнітною загрузкою, вздовж висоти корпусу при різних діаметрах корпусів. На основі принципу суперпозиції магнітних полів і графічних залежностей встановлено відстані між осердям суміжних електромагнітів при різних діаметрах корпусів. На основі досліджень запропоновано конструкцію електромагнітного фільтра з використанням тангенціальних електромагнітів, розміщених по відношенню до корпусу 3 загрузкою у взаємно перпендикулярних площинах. Запропоноване технічне рішення дозволяє створити по висоті корпусу у феромагнітній загрузці однакові умови для ефективного осадження магнітних домішок.

Ключові слова: феромагнітна загрузка, магнітні фільтри, осадження, індукція магнітного поля.

Для очищення водних середовищ від феродомішок відоме використання електромагнітних фільтр-осаджувачів з феромагнітними осердями $[1 ; 2 ; 3 ; 4 ; 5]$. Наявність осердь-магнітопроводів у формі С або П, в яких існують згини під кутом $90^{\circ}$ або іншим кутом, роз'єми, гвинтові з'єднання, призводить до значних втрат магнітного поля, що досягають, в окремих випадках, до 70\% [3; 5; 6].

Для визначення раціональних значень основних геометричних параметрів електромагнітних фільтрів з осердями і встановлення науково обґрунтованого співвідношення між діаметром корпусу (D), діаметром осердя електромагніта $\left(\mathrm{d}_{\mathrm{c}}\right)$, відстанню між осердями по висоті корпусу фільтра (L) виконані дослідження з вивчення характеру розподілу магнітного поля в циліндричних корпусах різного діаметру (D), заповнених феромагнітною загрузкою, при різних значеннях напруженості магнітного поля. Дослідження виконувались за методи- 
кою [3]. Результати вимірювання індукції магнітного поля в щілинному проміжку феромагнітної загрузки вздовж осі Z циліндричних корпусів різного діаметра $(x=0, y=0)$ наведено на рис. 1 [5].

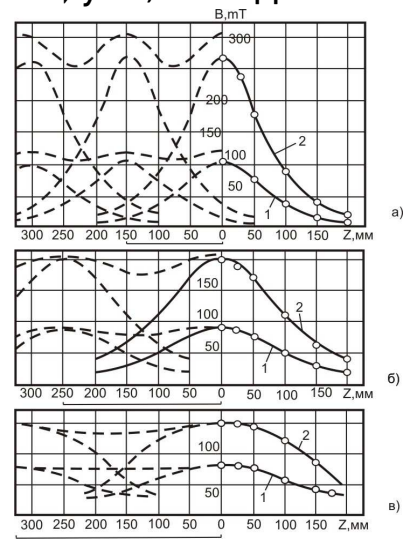

Рис. 1. Індукція магнітного поля в щілинному проміжку загрузки вздовж осі

$Z$ циліндричних корпусів різного діаметра (D) (x=0, y=0): a - D=120 мм;

$$
\text { б - 160; в - 240. 1-H=40 кA/м; } 2-160
$$

Полюси осердь електромагнітів при цих дослідженнях торцевою поверхнею щільно прилягали до поверхні циліндричного корпуcy.

Використовуючи принцип суперпозиції магнітних полів і графічні залежності рис. 1, встановлено відстані $L$ між осердями суміжних електромагнітів при різних діаметрах D корпусів. Розрахунками встановлено діаметри осердь-електромагнітів $d_{c}$ при різних значеннях напруженостей $\mathrm{H}$ полів і діаметрів корпусів, наведених в табл. 1.

Таблиця 1

Значення деяких конструктивних параметрів фільтрів в залежності від напруженості магнітного поля

\begin{tabular}{|c|c|c|c|c|c|c|}
\hline D, MM & 120 & 140 & 160 & 180 & 220 & 240 \\
\hline $\mathrm{L}, \mathrm{MM}$ & 120 & 200 & 250 & 270 & 300 & 320 \\
\hline $\mathrm{d}_{\mathrm{c} 1}, \mathrm{MM}$ & 80 & 85 & 86 & 88 & 89 & 90 \\
\hline $\mathrm{d}_{\mathrm{c} 2}, \mathrm{MM}$ & 86 & 91 & 93 & 94 & 95 & 96 \\
\hline
\end{tabular}

$\mathrm{d}_{\mathrm{c} 1}-$ при $\mathrm{H}=120 \mathrm{\kappa A} / \mathrm{m} ; \mathrm{d}_{\mathrm{c} 2}-\mathrm{H}=160$.

Використовуючи дані табл. 1, розрахуємо і покажемо графічно (рис. 2) залежність $L / d_{c}-D$.

Видно, що величина $L / d_{c}$ майже пропорційно зростає при збільшенні діаметра корпусу D до 140 мм. В подальшому при збільшенні $\mathrm{D}>140$ мм величина $L / d_{c}$ зростає повільніше. Так, при зміні $D$ від 140 до 180, величина $L / d_{c}$ збільшилась в 1,27, при зміні D від 180 до $220, L / d_{c}$ збільшилась в 1,13 рази. 


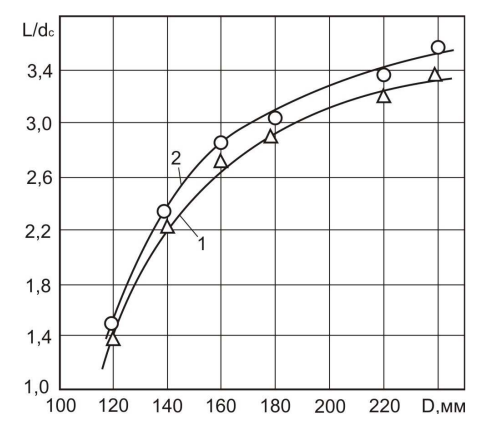

Рис. 2. До вибору діаметра осердя-магнітопроводу, міжосердної відстані, при різних значеннях діаметра корпусу: 1 - H=160 кА/м; 2 - 120 кА/м

Розрахункові і графічні залежності показують характер зміни індукції поля у феромагнітній загрузці, яка намагнічена електромагнітами, торцева частина яких прилягає до циліндричного корпусу, причому полюси електромагнітів розташовані протилежно на одній лінії (рис. 3, L=0). Водночас в літературі не виявлено результатів вимірювань індукції поля в загрузці, що намагнічена електромагнітами, які зміщені один відносно іншого по висоті корпусу фільтра ( $L \neq 0)$.

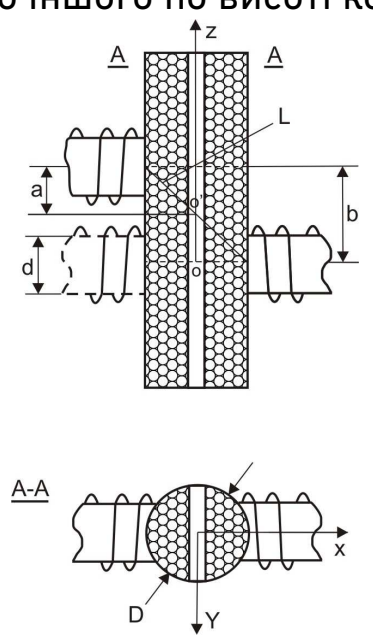

Рис. 3. Схема експериментальної установки з визначення характеру розподілу індукції магнітного поля в кульковій загрузці, розміщеній між полюсами торцевих електромагнітів

За відсутністю вказаних даних реалізовані власні досліди з вимірювання індукції магнітного поля у феромагнітній загрузці, розміщеній у циліндричному корпусі, до якого з протилежних сторін по діаметру розміщували електромагніти, полюси яких щільно прилягали до поверхні корпусу. Причому протилежно розміщені електромагніти зміщували один відносно іншого (рис. 3).

Величину зміщення L змінювали від 76 до 368 мм. По діаметра- 
льному перерізу вздовж осі Z (рис. 3) створювали щілинний проміжок для вимірювання індукції магнітного поля. Кількість ампервитків встановлювали I.W=3,84·104 A.в. Результати вимірювань наведено на рис. 4. При зміщенні полюсів електромагнітів на величину $\mathrm{L}=76$ мм індукція магнітного поля вздовж осі $Z$ від $\max$ до min значення зменшується в 3,9 рази при зміні z=0-200 мм (крива 4). Вимірювання індукції B при зміщенні на $L=368$ мм (рис. 4, крива 1) показує, що В зростає до Z=100 мм, в подальшому, при Z>100 мм В зменшується до 40 мТ, при Z=160 мм зміна В вздовж Z має параболоподібний характер. Для кривої 2, при L=272 мм спостерігається повільне зростання індукції поля В в напрямку Z до величини Z=160 мм, в подальшому при Z>160 мм В зменшується до величини 34 мТ ( $Z=280$ мм).

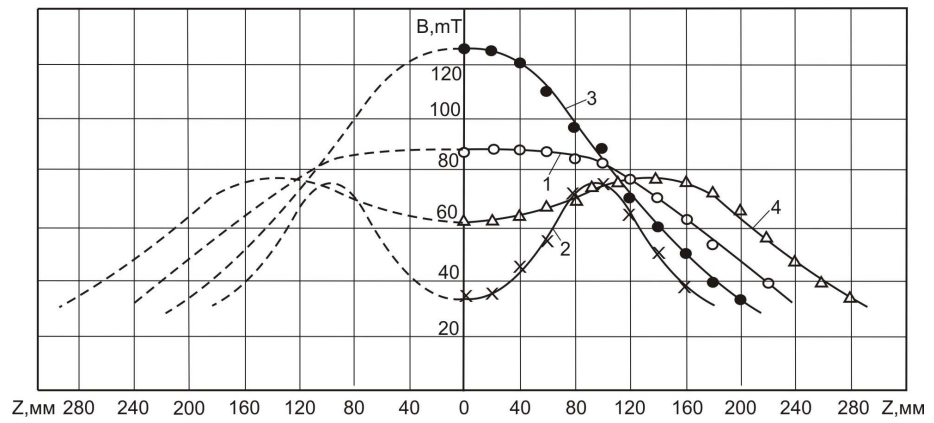

Рис. 4. Індукція магнітного поля в щілинному проміжку вздовж осі Z циліндричного корпусу, D=220 мм з феромагнітною загрузкою при різних зміщеннях (L) протилежних магнітних полюсів електромагнітів: 1 - 368 мм;

$$
2-272 ; 3-162 ; 4-76(x=0, y=0) . I \cdot W=3,84 \cdot 10^{4} A \cdot B
$$

Зміщення електромагнітів на $L=162$ мм показує (крива 3), що в загрузці вздовж Z існують зони, в яких індукція поля практично не змінюється. Так, зміна Z від 0 до 100 мм практично не призводить до зміни індукції поля. Така ж зона існує і вниз від т. 0 вздовж осі Z. Характер розподілу індукції поля при $L=162$ мм такий, що вздовж осі Z для такого розподілу раціонально використати принцип суперпозиції магнітних полів. Прості розрахунки показують, що наступний суміжний електромагніт з правої сторони корпусу (рис. 3) раціонально розмістити на відстані 440-450 мм. Таке розміщення дозволить створити вздовж осі Z зони однакової намагніченості. Технічно це реалізується таким чином: вздовж висоти корпусу фільтра з загрузкою в шахматному порядку розміщуються електромагніти з зміщенням між суміжними електромагнітами $L=440-450$ мм. В залежності від необхідної довжини фільтруючої загрузки електромагнітів може бути декілька. 
У вищенаведених дослідах полюси електромагнітів торцевою поверхнею прилягали до корпусів фільтра. Площа поверхні осердя електромагніту, що прилягає до корпуса обмежена діаметром осердя. В разі збільшення площі поверхні осердя виникає необхідність збільшення діаметру осердя, а це призводить до збільшення діаметра котушки і маси електромагніта, відповідно, і фільтра вцілому. Запропоновано полюса електромагнітів виготовляти з заглибленнями, що боковою поверхнею прилягають до корпусів $[7 ; 8 ; 9 ; 10]$. В цьому випадку площа поверхні електромагнітів, яка прилягає до корпусів, збільшується. Такі електромагніти отримали назву тангенціальних $[7 ; 8 ; 9 ; 10]$.

Експериментальну установку для досліджень характеру розподілу індукції магнітного поля у феромагнітній загрузці циліндричного корпусу, розміщеного між тангенціальними електромагнітами, зображено на рис. 5.

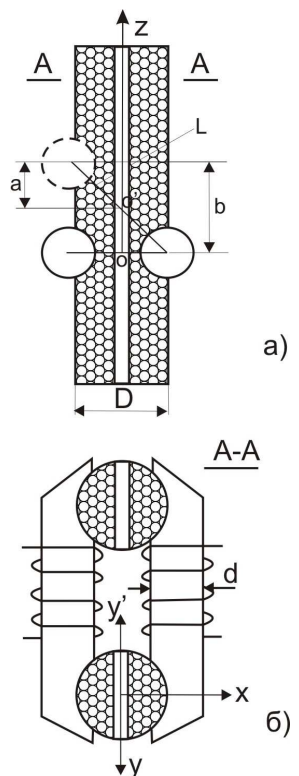

Рис. 5. Схема експериментальної установки з визначення характеру розподілу індукції магнітного поля у кульковій феромагнітній загрузці, розміщеній між полюсами тангенціальних електромагнітів

Вимірювання індукції поля виконували при $L=0$, що відповідало розміщенню електромагнітів один навпроти іншого по різні сторони циліндричного корпусу (рис. 5). По осі корпусу вздовж осі Z створювали щілинний проміжок для розміщення давача Холла. Результати вимірювання індукції вздовж осі Z наведено на рис. 6.

Видно, що при $Z=0$ індукція поля $B$ має $\max$ значення. При зміні $Z=0-240$ мм як вверх, так і вниз індукція зменшується в 5-6 разів. 3 
графічних залежностей (криві 1 і 3) видно, що наступну пару тангенціальних електромагнітів по висоті корпусу з загрузкою раціонально розміщувати на відстані 260-270 мм відносно першої пари електромагнітів.

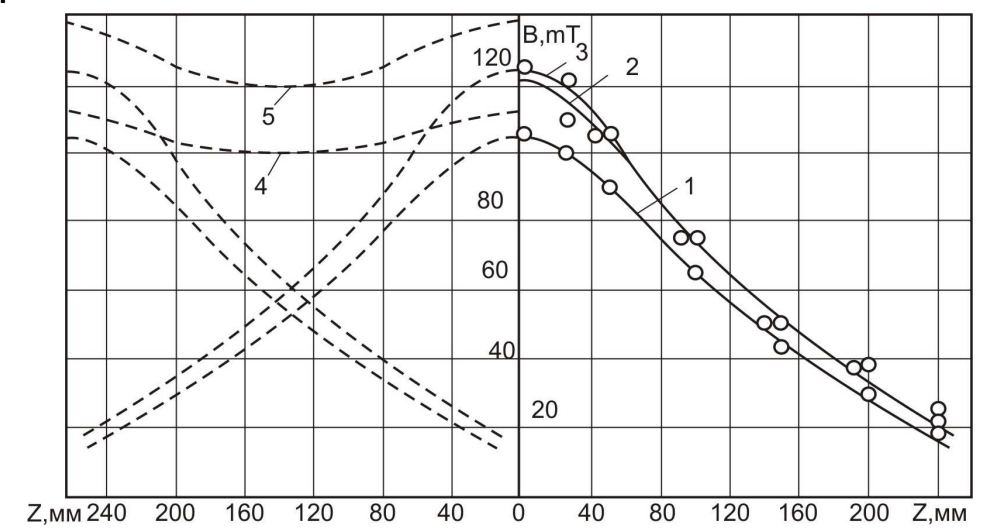

Рис. 6. Розподіл індукції магнітного поля в щілинному проміжку феромагнітної загрузки вздовж осі $Z$ корпусу $D=220$ мм $(X=0, Y=0, L=0): 1$ - напруженість поля $\mathrm{H}=44 \mathrm{KA} / \mathrm{M} ; 2-130 \mathrm{kA} / \mathrm{M} ; 3-175 \mathrm{kA} / \mathrm{M}$

При такому розміщенні електромагнітів результуюча індукція магнітного поля (внаслідок суперпозиції) вздовж осі Z буде змінюватись по кривим 4, 5 (рис. 6), крива 4, при напруженості Н магнітного поля - 44 кА/м, крива 5, при Н-175 кА/м. Зміну індукції поля вздовж осі $X$ при різних значеннях напруженості магнітного поля графічно показано на рис. 7. Видно, що від центра (0) корпусу в напрямку X, до полюса електромагніта індукція поля інтенсивно збільшується. Незалежно від зміни напруженості магнітного поля у вказаному діапазоні індукція в напрямку осі X збільшується в 1,7-1,8 рази (рис. 7).

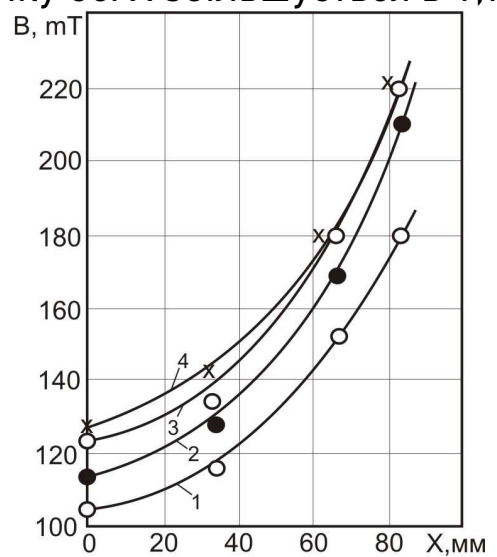

Рис. 7. Індукція магнітного поля в щілинному проміжку загрузки вздовж осі $X$ корпусу $\mathrm{D}=220 \mathrm{mм}(\mathrm{Y}=0 ; \mathrm{Z}=0)$ :

$1-\mathrm{H}=44 \mathrm{\kappa A} / \mathrm{m} ; 2-87 \mathrm{\kappa A} / \mathrm{m} ; 3-130 \mathrm{\kappa A} / \mathrm{m} ; 4-175 \mathrm{\kappa A} / \mathrm{M}$ 
Інший характер зміни індукції поля спостерігається вздовж осі Ү. Результати вимірювань індукції в напрямку осі $\mathrm{Y}$ наведено на рис. 8.

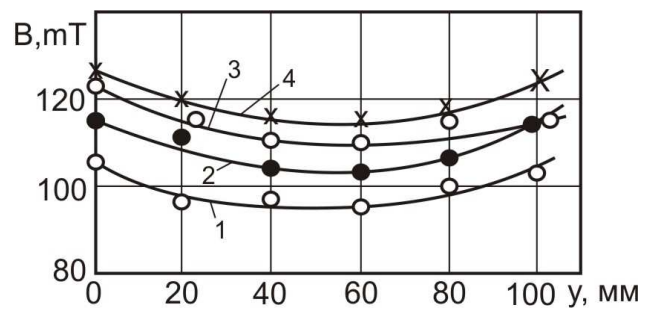

Рис. 8. Індукція магнітного поля в щілинному проміжку загрузки вздовж осі Y корпусу D=220 мм (X=0; Z=0): 1 - H=44 кA/м; 2 - 87 кA/м; 3 - 130 кA/м; $4-175 \mathrm{KA} / \mathrm{M}$

Індукція від центра (0) корпусу повільно зменшується в напрямку до $Y=40-60$ мм, в подальшому при $Y>60$ мм збільшується. Зміна індукції в напрямку $Y$ носить параболічний характер. Різниця між $\max i$ min значенням індукції вздовж Ү складає 10-11\%. Разом з тим, згідно вимірювання індукції вздовж Ү, при використанні електромагнітів, що торцевою поверхнею прилягають до корпуса, різниця між max i $\min$ значенням індукції складає 70-75\%.

Вимірювання індукції В вздовж Y' (рис. 5, б) показали, що величина В збільшена на 15-20\% в порівнянні з В вздовж Ү. В той же час характер зміни В однаковий як вздовж $Y$, так і вздовж $Y^{\prime}$. Збільшення В в напрямку $Y^{\prime}$ пояснюється тим, що більша на 15-20\% частина магнітного потоку проходить через об'єми феромагнітної загрузки, які розташовані ближче до джерела магнітного поля (котушки) і, відповідно, мають менший магнітний опір.

Порівнюючи результати вимірювання індукції магнітного поля у феромагнітній загрузці при використанні електромагнітів, які прилягають торцевою поверхнею до циліндричного корпусу (рис. 3), і тангенціальних електромагнітів (рис. 5), які боковою поверхнею прилягають до корпусу, можна зробити висновок, що при використанні тангенціальних електромагнітів феромагнітна загрузка намагнічена більш рівномірно, а зони загрузки (рис. 5, зона А), в яких намагніченість має низьке значення, зведені до мінімуму. Необхідно зазначити, що при використанні корпусів з більшим діаметром зони загрузки з низькою намагніченістю збільшуються.

Для вирівнювання намагніченості по об'єму загрузки і збільшення індукції поля запропоновано нове технічне рішення - розміщення тангенціальних електромагнітів відносно корпусу з загрузкою 
у взаємно перпендикулярних площинах. Схему магнітного фільтра 3 новим розміщенням тангенціальних електромагнітів наведено на рис. 9, а, б, в.

Магнітний фільтр складається з чотирьох циліндричних корпусів 1, заповнених феромагнітною загрузкою 2 (рис. 9). Нижня пара тангенціальних протилежно розміщених електромагнітів 4 по висоті циліндричного корпусу розміщена в одній площині, інша пара суміжних по висоті корпусу електромагнітів 5, 6 розміщена в перпендикулярній площині по відношенню до нижньої пари електромагнітів. В залежності від висоти корпусу фільтра, яка визначається необхідною довжиною фільтруючої загрузки, може бути декілька пар електромагнітів.

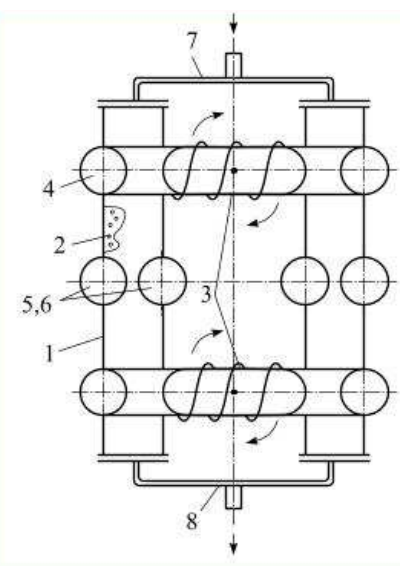

a)

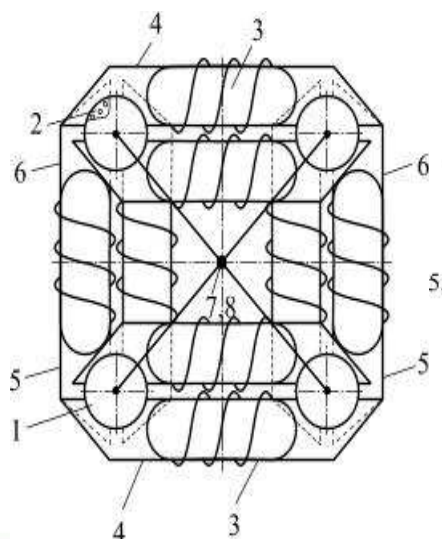

б)

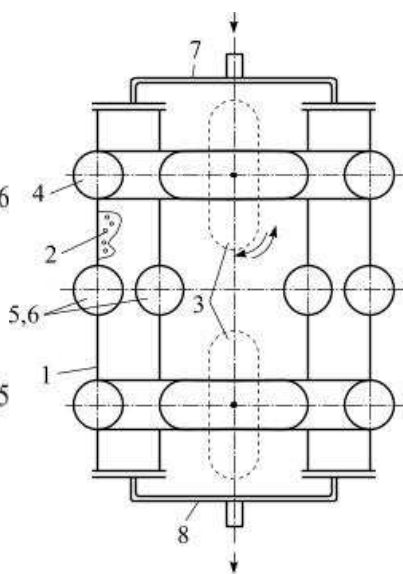

в)

Рис. 9. Магнітний фільтр з тангенціальним розміщенням електромагнітів: 1 - циліндричний корпус; 2 - феромагнітна загрузка; 3 - блоки постійних магнітів, встановлені з можливістю обертання; 4, 5, 6 - електромагніти; 7, 8 - вихідний і вхідний трубопроводи

Запропоноване нове технічне рішення дозволяє створювати по висоті корпусу у феромагнітній загрузці однакові умови для ефективного осадження магнітних домішок. При русі водного середовища магнітні домішки проходять зони фільтруючої загрузки, намагніченої нижніми електромагнітами 4 (рис. 9, а, б). Між полюсами цих електромагнітів індукція магнітного поля в загрузці змінюється вздовж X i Y так, як зображено на рис. 7; 8. При проходженні водного середовища через зони загрузки, які намагнічені електромагнітами 5 , 6, що розміщені у перпендикулярній площині характер зміни індукції магнітного поля в загрузці повернутий на $90^{\circ}$ по відношенню до попередніх намагнічених зон загрузки. Водне середовище, що очищується, по висоті фільтруючої загрузки послідовно проходить зони високої 114 
індукції магнітного поля, що сприяє ефективнішому очищенню від магнітних домішок.

Намагнічуюча система фільтра може бути виготовлена у вигляді блоків постійних магнітів (рис. 9, в) таким чином, що полюси магнітної системи жорстко прикріплені до корпусів фільтра, а блоки постійних магнітів встановлені з можливістю обертання на 90, розриваючи тим самим замкнений магнітний контур. Це необхідно для поліпшення процесу регенерації. Для зменшення залишкової намагніченості феромагнітної загрузки намагнічуюча система у вигляді електромагнітів виготовляється з рухомою середньою частиною, що розміщена між полюсами. Полюси намагнічуючої системи для підвищення рівня намагніченості загрузки рекомендується виготовляти 3 низьковуглецевого заліза, яке пройшло режим відпалювання. Полюси можуть бути також виготовлені з пермендюра або пермалою, які мають високу індукцію магнітного насичення. Залежно від об'єму водного середовища, що очищується, може бути декілька блоків корпусів (один блок - 4 корпуси).

1. А. с. 383468 СССР, МКИ В 03 С 1/12. Электромагнитный фильтрсепаратор / К. А. Блинов, М. Я. Полянский, В. С. Кириченко (СССР). № 1649423/24-6; заявл. 16.04.71; опубл. 23.05.73, Бюл. № 24. 2. А. с. 472668 СССР, М. кл. В 03 С 1/12. Электромагнитный фильтр / К. А. Блинов, М. Я. Полянский, В. С. Кириченко и др. (СССР). № 1974254/23-26; заявл. 15.08.73; опубл. 05.06.75, Бюл. № 21. 3. Гаращенко В. И. Исследование и внедрение новых фильтров с намагниченной пористой насадкой по осаждению железосодержащих примесей аммиачной воды реактивной чистоты и конденсата : автореф. дис. ... канд. техн. наук : спец. 05.17.08. К., 1981. 21 с. 4. Лапотышкина Н. П., Синицын В. С., Леглер Т. Б. Изучение условий электромагнитного обезжелезывания турбинного конденсата. Теплоэнергетика. 1973. № 5. С. 14-17. 5. Сандуляк А. В., Гаращенко В. И. Электромагнитные фильтры-осадители. Львов : Вища школа, 1982. 72с. 6. А. с. 472669 СССР, М.кл. В 03 С 1/12. Электромагнитный фильтр / К. А. Блинов, М. Я. Полянский, В. С. Кириченко и др. (СССР). № 1985344/23-26; заявл. 15.08.73; опубл. 05.06.75, Бюл. № 21. 7. А. с. № 1044310 А (СССР) МПК B01D 35/06. Электромагнитный фильтр-осадитель / В. И. Гаращенко, А. В. Сандуляк, И. Е. Вовк (СССР). № 3428724/23-26; заявл. 26.04.82. опубл. 30.09.83. Бюл. № 36. 8. А. с. 1088795 СССР, МПК В03 С 1/00. Сепаратор для магнитного разделения жидких сред / В. И. Гаращенко, А. В. Сандуляк, И. В. Волков (СССР). № 3442701/22-03; заявл. 27.05.82; опубл. 30.04.84, Бюл. № 16. 9. А. с. 1162492 СССР, МПК В03 С 1/30. Электромагнитный сепаратор / В. И. Гаращенко, А. В. Сандуляк, В. В. Сандуляк (СССР). № 3345487/22-03; заявл. 06.10.81; опубл. 23.06.85, Бюл. № 23. 10. А. С. 1504870 СССР, МПК В03 
C 1/00, B01 D 35/06. Магнитный фильтр-сепаратор для очистки жидкостей и газов от примесей / В. И. Гаращенко, А. В. Сандуляк, И. В. Волков (СССР). № 3877702/23-26; заявл. 22.04.85; ДСП.

\section{REFERENCES:}

1. A. s. 383468 SSSR, MKY V 03 S 1/12. Elektromahnitnyi filtr-separator / K. A. Blinov, M. Ya. Polianskii, V. S. Kirichenko (SSSR). № 1649423/24-6; zaiavl. 16.04.71; opubl. 23.05.73, Biul. № 24. 2. A. s. 472668 SSSR, M. kl. V 03 S 1/12. Elektromahnitnyi filtr / K. A. Blinov, M. Ya. Polianskii, V. S. Kirichenko i dr. (SSSR). № 1974254/23-26; zaiavl. 15.08.73; opubl. 05.06.75, Biul. № 21. 3. Harashchenko V. I. Issledovanie i vnedrenie novykh filtrov s namahnichennoi poristoi nasadkoi po osazhdeniiu zhelezosoderzhashchikh primesei ammiachnoi vody reaktivnoi chistoty i kondensata : avtoref. dis. ... kand. tekhn. nauk : spets. 05.17.08. K., 1981. 21 s. 4. Lapotyshkina N. P., Sinitsyn V. S., Lehler T. B. Izuchenie uslovii elektromahnitnoho obezzhelezyvaniia turbinnoho kondensata. Teploenerhetika. 1973. № 5. S. 14-17. 5. Sanduliak A. V., Harashchenko V. I. Elektromahnitnye filtry-osaditeli. Lvov : Vyshcha shkola, 1982. 72s. 6. A. s. 472669 SSSR, M. kl. V 03 S 1/12. Elektromahnitnyi filtr / K. A. Blinov, M. Ya. Polianskii, V. S. Kirichenko i dr. (SSSR). № 1985344/23-26; zaiavl. 15.08.73; opubl. 05.06.75, Biul. № 21. 7. A. s. № 1044310 A (SSSR) MPK V01D 35/06. Elektromahnitnyi filtrosaditel / V. I. Harashchenko, A. V. Sanduliak, I. E. Vovk (SSSR). № 3428724/23-26; zaiavl. 26.04.82. opubl. 30.09.83. Biul. № 36. 8. A. s. 1088795 SSSR, MPK V03 S 1/00. Separator dlia mahnitnoho razdeleniia zhidkikh sred / V. I. Harashchenko, A. V. Sanduliak, I. V. Volkov (SSSR). № 3442701/22-03; zaiavl. 27.05.82; opubl. 30.04.84, Biul. № 16. 9. A. s. 1162492 SSSR, MPK V03 S 1/30. Elektromahnitnyi separator / V. I. Harashchenko, A. V. Sanduliak, V. V. Sanduliak (SSSR). № 3345487/22-03; zaiavl. 06.10.81; opubl. 23.06.85, Biul. № 23. 10. A. s. 1504870 SSSR, MPK V03 S 1/00, V01 D 35/06. Mahnitnyi filtr-separator dlia ochistki zhidkostei i hazov ot primesei / V. I. Harashchenko, A. V. Sanduliak, I. V. Volkov (SSSR). № 3877702/23-26; zaiavl. 22.04.85; DSP.

Harashchenko O. V., Candidate of Engineering (Ph.D.), Harashchenko V. I., Candidate of Engineering (Ph.D.), Associate Professor, Safonyk A. P., Doctor of Engineering, Professor,

Soliak L. V., Senior Lecturer (National University of Water and Environmental Engineering, Rivne)

EXPERIMENTAL RESEARCHES OF ELECTROMAGNETIC FILTER PARAMETERS 
For the purification of liquid media from ferromagnetic impurities, it is proposed to use electromagnetic filter-precipitators with tangential ferromagnetic cores which adjacent of its poles lateral surface to the cylindrical surfaces of the filter body. The results of researches on the distribution of magnetic field induction in a cylindrical body filled with a ferromagnetic nozzle on the height of the body at different body diameters are presented. The poles of the cores of the electromagnets with the face surface are close to the surface of the cylindrical body. On the basis of the principle of superposition of magnetic fields and graphical dependences, distances between the cores of adjacent electromagnets at different body diameters were established. The diameters of the cores of electromagnets at different values of field tension and body diameters were calculated. The researches established the character of the magnetic field induction distribution in a ferromagnetic nozzle holded in a cylindrical body, to which electromagnetic poles are placed on opposite sides. Measurements shows that when electromagnets shifted by $162 \mathrm{~mm}$ from each other in the nozzle there are areas in which the induction is practically unchanged. This allows to place the adjacent electromagnets at such a distance that, along the axis of the body, the ferromagnetic nozzle zones will have the same magnetization. This distance is $440-450 \mathrm{~mm}$. Depending on the required length of the filter nozzle electromagnets may be several. It is proposed to install the poles of the electromagnets with the special recesses adjacent to the side surface of the filer body, which allows to increase the surface area of the electromagnets. This reduces the number of zones in the volume of ferromagnetic nozzle with a minimum value of field induction. This allows, by means of the superposition principle, to establish a rational placement of the electromagnets along the height of the filter body, in which the filter nozzle is magnetized uniformly. Based on the research, the design of the electromagnetic filter using tangential electromagnets placed in the perpendicular planes with filter body is proposed. The proposed technical solution allows to create the same conditions for all height of ferromagnetic nozzle for efficient deposition of magnetic impurities.

Keywords: ferromagnetic nozzle, magnetic filter, deposition, induction of magnetic field. 
Гаращенко А. В., к.т.н, Гаращенко В. И., к.т.н., доцент, Сафоник А. П., д.т.н., профессор, Соляк Л. В., ст. преподаватель (Национальный университет водного хозяйства и природопользования, г. Ровно)

\section{ЭКСПЕРИМЕНТАЛЬНЫЕ ИССЛЕДОВАНИЯ ПАРАМЕТРОВ ЭЛЕКТРОМАГНИТНЫХ ФИЛЬТРОВ}

Приведены результаты исследований по распределению индукции магнитного поля в цилиндрическом корпусе, заполненном ферромагнитной загрузкой по высоте корпуса при различных диаметрах корпусов. На основе принципа суперпозиции магнитных полей и графических зависимостей установлены расстояния между сердечниками смежных электромагнитов при различных диаметрах корпусов. На основе исследований предложена конструкция электромагнитного фильтра с использованием тангенциальных электромагнитов расположенных по отношению к корпусу с загрузкой во взаимно перпендикулярных плоскостях. Предложенное техническое решение позволяет создать по высоте корпуса в ферромагнитной загрузке одинаковые условия для эффективного осаждения магнитных примесей.

Ключевые слова: ферромагнитная загрузка, магнитный фильтр, осаждение, индукция магнитного поля. 